\title{
$\Psi$-Xenin-6 enhances sitagliptin effectiveness, but does not improve glucose tolerance
}

\author{
Sarah L Craig1, Victor A Gault ${ }^{1}$, Gerd Hamscher ${ }^{2}$ and Nigel Irwin ${ }^{1}$ \\ 1SAAD Centre for Pharmacy and Diabetes, University of Ulster, Coleraine, Northern Ireland, UK \\ 2Institute of Food Chemistry and Food Biotechnology, Justus Liebig University Giessen, Giessen, Germany
}

Correspondence should be addressed to N Irwin: n.irwin@ulster.ac.uk

\begin{abstract}
Recent studies have characterised the biological properties and glucose-dependent insulinotropic polypeptide (GIP) potentiating actions of an enzymatically stable, C-terminal hexapeptide fragment of the gut hormone xenin, namely $\Psi$-xenin-6. Given the primary therapeutic target of clinically approved dipeptidyl peptidase-4 (DPP-4) inhibitor drugs is augmentation of the incretin effect, the present study has assessed the capacity of $\Psi$-xenin- 6 to enhance the antidiabetic efficacy of sitagliptin in high fat fed (HFF) mice. Individual administration of either sitagliptin or $\Psi$-xenin- 6 alone for 18 days resulted in numerous metabolic benefits and positive effects on pancreatic islet architecture. As expected, sitagliptin therapy was associated with elevated circulating GIP and GLP-1 levels, with concurrent $\Psi$-xenin- 6 not elevating these hormones or enhancing DPP-4 inhibitory activity of the drug. However, combined sitagliptin and $\Psi$-xenin- 6 therapy in HFF mice was associated with further notable benefits, beyond that observed with either treatment alone. This included body weight change similar to lean controls, more pronounced and rapid benefits on circulating glucose and insulin as well as additional improvements in attenuating gluconeogenesis. Favourable effects on pancreatic islet architecture and peripheral insulin sensitivity were more apparent with combined therapy. Expression of hepatic genes involved in gluconeogenesis and insulin action were partially, or fully, restored to normal levels by the treatment regimens, with beneficial effects more prominent in the combination treatment group. These data demonstrate that combined treatment with $\Psi$-xenin- 6 and sitagliptin did not alter glucose tolerance but does offer some metabolic advantages, which merit further consideration as a therapeutic option for type 2 diabetes.
\end{abstract}

$\begin{aligned} & \text { Key Words } \\ & \text { - beta-cell } \\ & \text { - diabetes } \\ & \text { - DPP-4 } \\ & \text { - insulin } \\ & \text { - xenin }\end{aligned}$

Journal of Endocrinology (2020) 245, 219-230

\section{Introduction}

Dipeptidyl peptidase-4 (DPP-4) inhibitors are an orally available class of drugs, clinically approved for the treatment of type 2 diabetes mellitus (T2DM) (Scott 2017). The primary therapeutic benefit of DPP-4 inhibitors in T2DM relates to preventing degradation and subsequent loss of bioactivity of the endogenous intestinal-derived incretin hormones, glucagon-like peptiede-1 (GLP-1) and glucose-dependent insulinotropic polypeptide (GIP) (Deacon 2019). Thus, GLP-1 and GIP stimulate glucose-dependent insulin secretion and improve glycaemic status, resulting in reduced glycated haemoglobin concentrations (Baggio \& Drucker 2007). These hormones also exert a number of extrapancreatic actions that have beneficial glucose homeostatic effects (O’Harte et al. 1998, Baggio \& Drucker 2007). 
However, a key pathophysiological aspect of T2DM relates to an impaired incretin effect (Holst \& Ørskov 2004). As such, circulating levels of GLP-1 are believed to be reduced in T2DM, while the insulinotropic effects of GIP are severely diminished (Knop et al. 2007). DPP-4 inhibition will increase circulating concentrations of biologically active GLP-1 (Ahrén 2007), but does not correct GIP insensitivity in T2DM. In this regard, a related 25 amino acid gut-derived hormone known as xenin has been shown to augment the biological actions of GIP in vitro and in vivo (Wice et al. 2010, Martin et al. 2012, Gault et al. 2015a). In addition, xenin also independently stimulates insulin secretion and supresses appetite (Taylor et al. 2010, Martin et al. 2012, 2014, 2016, Gault et al. 2015b, Craig et al. 2018), which would be further advantageous in T2DM. Unlike GIP and GLP-1, xenin is not degraded by DPP-4 (Taylor et al. 2010), and thus DPP-4 inhibitors do not alter circulating xenin levels. However, enzymatic degradation fragment peptides of xenin are present in plasma (Martin et al. 2012), with some of these shown to retain the parent peptide biological action profile (Martin et al. 2014, 2016, Parthsarathy et al. 2016, Craig et al. 2019). In this regard, xenin- 6 appears to be the shortest xenin form that recapitulates the key physiological actions of xenin at the level of the endocrine pancreas (Craig et al. 2019).

Recent studies in our laboratory (Craig et al. 2019) have followed up on the initial characterisation of an enzymatically stabilised xenin-6 form, namely $\Psi$-xenin-6 (Feurle et al. 2003). $\Psi$-Xenin-6 is a C-terminal hexapeptide of xenin with a reduced pseudopeptide bond $\left(\mathrm{CH}_{2} \mathrm{NH}\right)$ positioned between the first two N-terminal amino acid residues that possesses a significantly extended pharmacokinetic profile (Feurle et al. 2003). In our hands, $\Psi$-xenin-6 stimulated insulin secretion from in vitro and $e x$ vivo systems, promoted beta-cell proliferation and survival, augmented glucose homeostasis, insulin secretion and satiety in rodents as well as amplified the insulinotropic actions of GIP (Craig et al. 2019). Thus, combination therapy with a DPP-4 inhibitor and $\Psi$-xenin-6 represents an exciting potential therapeutic option for T2DM. Recent positive advances in the field of peptide hormone therapeutics and T2DM relate to the targeting of multiple receptor signalling pathways (Bhat et al. 2013, Irwin et al. 2015, Khajavi et al. 2017, Coskun et al. 2018, Frias et al. 2018). Such strategies linked to observations of rapid remission of T2DM subsequent to certain types of bariatric surgeries, being directly associated with distinct changes in the secretion and action of numerous gutderived peptide hormones (Vincent \& Le Roux 2008, Knop \& Taylor 2013).
In the current study we have created a novel and targeted combinational therapeutic approach by employing $\Psi$-xenin-6 administration alongside the established DPP-4 inhibitor sitagliptin. We hypothesised that the complementary biological actions of both compounds would significantly improve diabetic status beyond that observed with either treatment alone. Thus, the major benefit of sitagliptin in diabetes therapy relates specifically to GLP-1 induced effects (Bennettt 2018), whereas $\Psi$-xenin- 6 will promote additional antidiabetic actions of the increased GIP levels encouraged by sitagliptin. As such, our primary objective was to examine the therapeutic efficacy of a 18-day combined administration of $\Psi$-xenin-6 and sitagliptin in high fat fed (HFF) mice. Effects on body weight, energy intake, circulating glucose, insulin, GIP and GLP-1, as well as glucose and pyruvate tolerance, peripheral insulin sensitivity, expression of key genes involved in liver glucose metabolism and insulin action, as well as DPP-4 activity and pancreatic islet morphology were assessed.

\section{Research design and methods}

\section{Animals studies}

Animal studies were conducted in male C57BL/6 mice (10-12 weeks old, Envigo Ltd, London, UK, $n=8$ ). Prior to commencement of experiments, mice were given free access to high fat diet (45\% fat, 20\% protein and 35\% carbohydrate, Special Diet Services, Witham, Essex, UK) for 4 weeks. During this 4 -week period, HFF mice then received a low dose streptozotocin (STZ) injection $(4 \mathrm{~h}$ fast, $50 \mathrm{mg} / \mathrm{kg}$ bw, i.p., in sodium citrate buffer, $\mathrm{pH} 4.5$ ) on week 2 of high fat feeding, with a second STZ injection ( $4 \mathrm{~h}$ fast, $75 \mathrm{mg} / \mathrm{kg}$ bw, i.p., in sodium citrate buffer, $\mathrm{pH}$ 4.5) on week 3. Mice exhibiting blood glucose concentrations greater than $11.1 \mathrm{mM}$ at the end of the 4-week period were then recruited onto the study and termed 'HFF mice' throughout. It would have been interesting to investigate pancreatic islet architecture at this point, prior to treatment initiation, but this was not possible in the current study. An additional group of mice $(n=8)$ were maintained on normal laboratory chow throughout $(10 \%$ fat, $30 \%$ protein and $60 \%$ carbohydrate, Trouw Nutrition, Ashbourne, Derbyshire, UK). These mice received buffer saline injection instead of STZ and were employed as gold standard controls. All mice were housed individually in an air-conditioned room at $22 \pm 2^{\circ} \mathrm{C}$ with a $12 \mathrm{~h}$ light: $12 \mathrm{~h}$ darkness cycle and experiments were carried out in accordance with the UK Animals Scientific Procedures Act 
1986. Studies were approved by the University of Ulster Animal Welfare and Ethical Review Body (AWERB). No adverse effects were observed after drug treatment.

\section{Experimental design}

HFF mice $(n=8)$ received oral sitagliptin phosphate monohydrate once daily $(50 \mathrm{mg} / \mathrm{kg}$ bw; ApexBio Technology, Houston, TX, USA; >97\% purity; MW 523.3; CAS No. 654671-77-9), intraperitoneal (i.p.) $\Psi$-xenin-6 twice daily ( $25 \mathrm{nmol} / \mathrm{kg}$ bw, Saxon Biochemicals, Hannover, Germany) or a combination of both compounds using the same dosing regimen for 18 days. All twice daily treatments were administered at 09:30 $\mathrm{h}$ and 17:00 $\mathrm{h}$, with once daily treatments delivered at 09:30 h. Saline vehicle $(0.9 \% \mathrm{w} / \mathrm{v}$, $\mathrm{NaCl}$; i.p. or oral) was administered as control at each time point either orally or intraperitoneally, as appropriate. Doses of sitagliptin and $\Psi$-xenin- 6 were chosen based on previous published studies in mice (Gault et al. 2015b, Craig et al. 2019). Lean control mice $(n=8)$ were also administered saline vehicle twice daily (orally at 09:30 $\mathrm{h}$ and i.p. at 17:00 h) throughout the study. Cumulative energy intake, body weight, circulating glucose and insulin concentrations were assessed at regular intervals during the study. At the end of the treatment period, glucose tolerance ( $18 \mathrm{mmol} / \mathrm{kg}$ bw; i.p.; $18 \mathrm{~h}$-fasted mice), insulin sensitivity ( $25 \mathrm{U} / \mathrm{kg}$ bovine insulin; i.p.; non-fasted mice) and pyruvate tolerance ( $2 \mathrm{~g} / \mathrm{kg}$ sodium pyruvate; i.p.; $18 \mathrm{~h}$-fasted mice) were assessed. HOMA-IR, fasting glucose $(\mathrm{mmol} / \mathrm{L}) \times$ fasting insulin $(\mathrm{mU} / \mathrm{L}) / 22.5$, was also calculated as a surrogate marker of insulin resistance. Terminal analyses included extraction of pancreatic tissue with appropriate processing for measurement of hormone content following acid/ethanol protein extraction or islet architecture, as described previously (Khan et al. 2017). Tissue blocks were sectioned $(7 \mu \mathrm{m})$ using a Shandon Finesse 325 microtome (Thermo Scientific) and picked for staining at intervals of ten sections. Approximately 60-80 islets were analysed per group. In addition, liver tissue was processed for hepatic gene expression by quantitative PCR after total RNA extraction, as described previously (Moffett et al. 2013). RealTime ready quantitative PCR target-specific primers (Roche Diagnostics) included: phosphoenolpyruvate carboxykinase (Pepck), glucose 6-phosphatase (G6pase), insulin receptor substrate-1 (Irs1), fibroblast growth factor 21 (Fgf21) and serinethreonine protein kinase (Akt1). $\beta$-Actin $(A c t b)$ was used as an internal control for normalisation. PCR conditions were $95^{\circ} \mathrm{C}$ for $10 \mathrm{~min}$, followed by cDNA amplification for 45 cycles with $95^{\circ} \mathrm{C}$ denaturation for $10 \mathrm{~s}, 60^{\circ} \mathrm{C}$ annealing for $30 \mathrm{~s}$ and $72^{\circ} \mathrm{C}$ elongation for $1 \mathrm{~s}$, followed by $30 \mathrm{~s}$ cooling at $40^{\circ} \mathrm{C}$. Relative quantification using the $2^{-\Delta \Delta \mathrm{CT}}$ (two delta, delta comparative test) method was used to calculate differences in gene expression between samples.

\section{Biochemical analysis}

Blood samples were collected from the cut tip of the tail vein of conscious mice into chilled fluoride/heparin glucose microcentrifuge tubes (Sarstedt, Numbrecht, Germany). Blood glucose was measured directly using a Contour blood glucose meter. For plasma insulin analysis, blood samples were collected into chilled fluoride/heparin glucose microcentrifuge tubes (Sarstedt, Numbrecht, Germany) and immediately centrifuged using a Beckman microcentrifuge (Beckman Instruments) for $1 \mathrm{~min}$ at $13,000 \boldsymbol{g}$ and stored at $-20^{\circ} \mathrm{C}$. Plasma and pancreatic insulin were then assayed using a modified dextrancoated charcoal RIA (Flatt \& Bailey 1982). Total GLP-1 and GIP plasma concentrations were determined using specific enzyme linked immunoassays (GLP-1 Total ELISA, EZGLP-1T-36K, Millipore; Rat/mouse GIP (Total) ELISA, EZRMGIP-55K, Millipore), following manufacturer's instructions. DPP-4 activity of terminal plasma, as well as sitagliptin and $\Psi$-xenin- 6 alone and in combination in vitro (both at $10^{-6} \mathrm{M}$ ), were determined using a fluorometric assay that measures free 7-amino-4-methyl-coumarin (AMC) liberated from Gly-Pro-AMC substrate, as described in more detail previously (Lindsay et al. 2005). Briefly, $10 \mu \mathrm{L}$ of plasma $(n=8)$ or peptide $(n=4)$ sample, where appropriate, was incubated with $30 \mu \mathrm{L}$ of Tris- $\mathrm{HCl}$ buffer (0.02 M, pH 8.0) containing $0.10 \mathrm{M} \mathrm{NaCl}$ and $1 \mathrm{mM}$ EDTA and $50 \mu \mathrm{L}$ of H-Gly-Pro-AMC $(200 \mu \mathrm{M})$. Following $5 \mathrm{~min}$ incubation at $37^{\circ} \mathrm{C}$, the reaction with the peptide samples was initiated by addition of $10 \mu \mathrm{L}$ DPP-4 $\left(8 \mathrm{mU} \mathrm{mL}^{-1}\right)$. The change in fluorescence was monitored over a 30-min period using a plate reader at excitation and emission wavelengths of 360 and $460 \mathrm{~nm}$, respectively.

\section{Statistical analysis}

Statistical analysis was completed using GraphPad PRISM (Version 5). Results are expressed as means \pm S.E.M. and data compared using repeated measures ANOVA followed by the Student-Newman-Keuls post-hoc test. The unpaired Student $t$-test was used where appropriate. Area under curve (AUC) and area above curve (AAC) analyses were calculated using appropriate baseline subtraction. Groups of data were considered to be significantly different if $P<0.05$. 


\section{Results}

Effects of $\Psi$-xenin-6, sitagliptin or a combination of both compounds on body weight, energy intake, glucose and insulin concentrations in HFF mice

Increases of body weight were significantly $(P<0.01$ to $P<0.001)$ reduced in HFF mice treated with $\Psi$-xenin-6, sitagliptin or a combination of both drugs by day 18 , when compared to HFF saline controls (Fig. 1A). Notably, in the combination treatment group, but not with monotherapy, percentage body weight increase was not significantly different from lean control mice (Fig. 1A). Energy intake was elevated $(P<0.01$ to $P<0.001)$ in all HFF mice compared to lean controls, but not significantly different between HFF groups (Fig. 1B). Non-fasting glucose levels were reduced to lean control levels in a time-dependent manner by all treatments, but this was more prominent in the combined treatment group with benefits evident from day 12 (Fig. 1C), with only the combined treatment group significantly reduced $(P<0.05)$ on day 18 compared to HFF mice (Fig. 1C). In addition, all HFF treatment groups exhibited progressive increases in insulin concentrations, with levels significantly $(P<0.05$ to $P<0.001)$ elevated compared to HFF saline controls from day 7 onward (Fig. 1D). Moreover, in HFF mice treated with $\Psi$-xenin-6 in combination with sitagliptin, circulating insulin was not significantly different to lean control mice by day 18 (Fig. $1 D)$ and were significantly increased $(P<0.05)$ compared to all other treatment groups (Fig. 1D).

\section{Effects of $\Psi$-xenin-6, sitagliptin or a combination of both compounds on glucose and pyruvate tolerance, insulin sensitivity as well as pancreatic insulin content in HFF mice}

Treatment of HFF mice with $\Psi$-xenin-6, sitagliptin or a combination of both drugs for 18 days resulted in reductions $(P<0.05$ to $P<0.01)$ of individual and overall

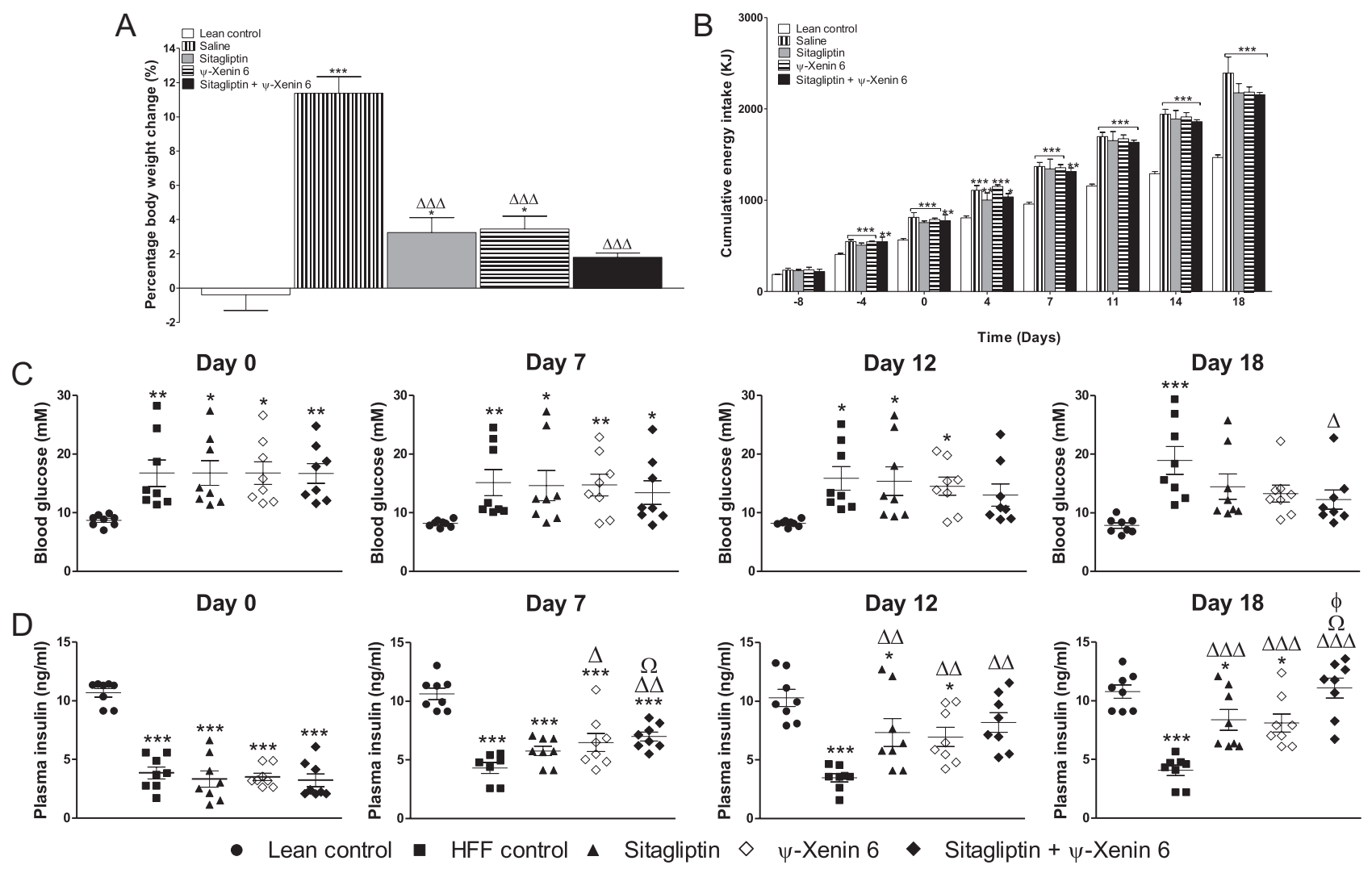

Figure 1

Effects of 18-day treatment with $\Psi$-xenin-6, sitagliptin or a combination of both compounds on (A) body weight, (B) energy intake, (C) glucose and (D) insulin concentrations in HFF mice. Parameters were measured during 18 days of treatment with sitagliptin ( $50 \mathrm{mg} / \mathrm{kg}$ bw, p.o., once daily), $\Psi$-xenin-6 (25 $\mathrm{nmol} / \mathrm{kg}$ bw. i.p. twice daily) or a combination of both compounds using the same dosing regimens. Values are mean \pm s.E.M. for eight mice. $* P<0.05$, $\star \star P<0.01$ and $* \star * P<0.001$ compared to lean controls. $\Delta P<0.05, \Delta \Delta P<0.01$ and $\Delta \Delta \Delta P<0.001$ compared to HFF saline controls. $\Omega P<0.05$ compared to sitagliptin alone. $\phi P<0.05$ compared to $\Psi$-xenin- 6 alone. 
A
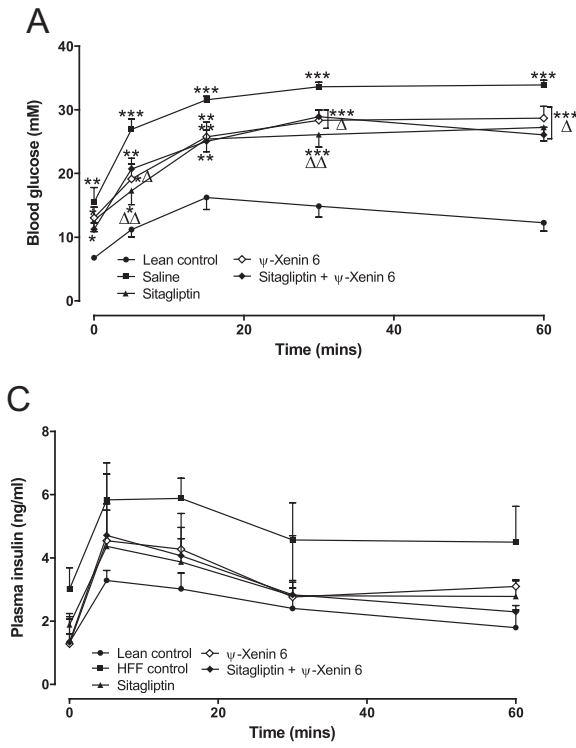

glucose levels when compared to saline HFF controls following an i.p. glucose load (Fig. 2A and B). However, glucose disposal was still impaired in all HFF mice when compared to lean controls (Fig. 2A and B). Interestingly, corresponding glucose-induced insulin levels were not significantly different between all groups of mice at each of the observation time points (Fig. 2C). However, overall 0-60 min AUC insulin concentrations were elevated $(P<0.01)$ in saline treated HFF mice when compared to all other groups of mice (Fig. 2D). When challenged with a pyruvate load on day 18 , only combined treatment with $\Psi$-xenin-6 and sitagliptin resulted in a significant decrease $(P<0.05$ to $P<0.001)$ in glucose levels when compared to HFF control mice at 30, 60 and 120 min post-injection (Fig. 3A). Overall 0-120 min blood glucose AUC values were reduced $(P<0.05$ to $P<0.001)$ by all treatment interventions, but still elevated $(P<0.01$ to $P<0.001)$ when compared to lean control mice (Fig. 3B). However, combination treatment was significantly reduced $(P<0.05)$ when compared to sitagliptin monotherapy (Fig. 3B). Peripheral insulin sensitivity was improved $(P<0.05$ to $P<0.001)$ by all treatment interventions (Fig. $4 \mathrm{~A})$, although administration of sitagliptin alone, or in combination with $\Psi$-xenin-6, resulted in similar glucoselowering effects of exogenous insulin as observed in lean control mice (Fig. 4A). HOMA-IR was also significantly $(P<0.05$ to $P<0.01)$ improved in all HFF treatment groups and not different from lean control mice (Fig. 4B). Pancreatic insulin content was similar to lean control mice in all HFF treatment groups and significantly elevated $(P<0.001)$ when compared to saline treated HFF mice (Fig. 4C).

\section{Effects of $\Psi$-xenin-6, sitagliptin or a combination of both compounds on pancreatic islet histology in HFF mice}

Images of pancreatic islets stained for insulin and glucagon from all groups of mice are shown in Fig. 5A, B, C, D and E. Visual inspection of these images illustrates dramatically reduced insulin staining in HFF saline treated mice when compared to lean controls (Fig. 5A and B). Following appropriate quantification, it was revealed that HFF saline mice had significantly reduced overall islet $(P<0.05)$ and beta-cell $(P<0.01)$ areas when compared to lean controls (Fig. 5F and $\mathrm{G}$ ). All treatment interventions returned islet and beta-cell area to normal levels (Fig. 5F and G). Alpha-cell area was increased in HFF saline $(P<0.001)$ and sitagliptin $(P<0.05)$ treated mice, but similar to lean controls in HFF mice treated with $\Psi$-xenin- 6 alone or in combination with sitagliptin (Fig. 5H). Beta to alphacell ratios were significantly $(P<0.001)$ increased by all treatments when compared to HFF controls and by $\Psi$-xenin-6 alone or in combination with sitagliptin, when compared to sitagliptin alone $(P<0.001)$, but still reduced $(P<0.001)$ when compared to lean control mice (Fig. 5I). Islet size distribution was comparatively similar in all groups of mice, but all HFF mice administered treatment did have reduced $(P<0.05$ to $P<0.01)$ numbers of smaller sized islets when compared to saline HFF controls (Fig. 5J). 

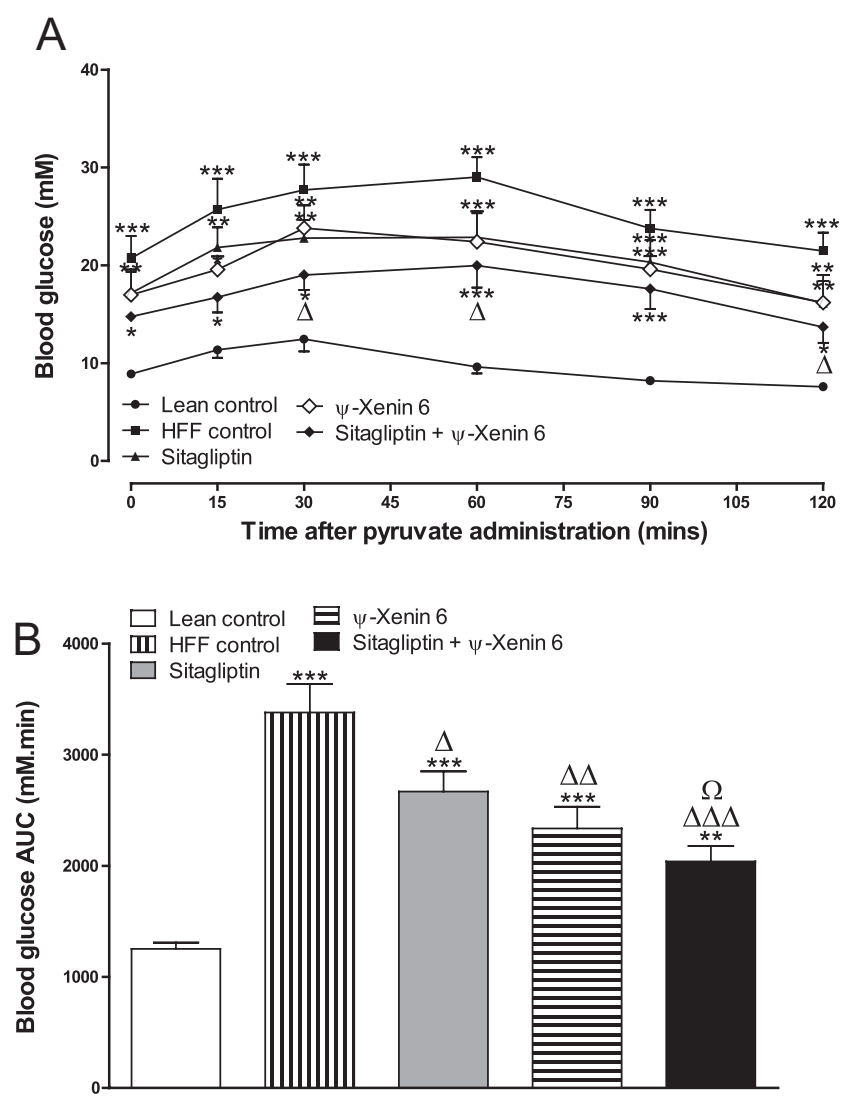

Figure 3

Effects of 18-day treatment with $\Psi$-xenin-6, sitagliptin or a combination of both compounds on pyruvate tolerance in HFF mice. Parameters were assessed following 18 days of treatment with sitagliptin $(50 \mathrm{mg} / \mathrm{kg}$ bw, p.o., once daily), $\Psi$-xenin-6 (25 nmol/kg bw. i.p. twice daily) or a combination of both compounds using the same dosing regimens. ( $A$ ) Pyruvate ( $2 \mathrm{~g} / \mathrm{kg}$ bw sodium pyruvate) was administered by i.p. injection at $\mathrm{t}=0 \mathrm{~min}$ in 18-h fasted mice. (B) Blood glucose AUC values for 0-120 min post injection are shown. Values are mean \pm s.E.M. for eight mice. $\star P<0.05, * \star P<0.01$ and $* \star \star P<0.001$ compared to lean controls. $\Delta P<0.05, \Delta \Delta P<0.01$ and $\Delta \Delta \Delta P<0.001$ compared to HFF saline controls. $\Omega P<0.05$ compared to sitagliptin alone.

\section{Effects of $\Psi$-xenin-6, sitagliptin or a combination of both compounds on expression of hepatic genes involved in gluconeogenesis and insulin action in HFF mice}

As would be expected, high fat feeding increased $(P<0.01$ and $P<0.05$, respectively) hepatic expression of Pepck and G6pase (Fig. 6A and B). All treatment interventions significantly $(P<0.05)$ reduced Pepck mRNA levels (Fig. $6 \mathrm{~A})$, but only combined $\Psi$-xenin-6 and sitagliptin therapy reduced $(P<0.05)$ G6pase expression, and returned expression of both genes to lean control levels (Fig. 6A and B). In addition, Irs1 hepatic expression levels were increased $(P<0.01)$ in all HFF treatment groups when compared to saline controls (Fig. 6C). Interestingly, only combination therapy increased $(P<0.001) \quad F g f 21$ and decreased $(P<0.01) A k t 1$, hepatic mRNA levels compared to HFF control mice (Fig. 6D and E). Indeed, expression levels of both genes were similar to lean control mice in the combined $\Psi$-xenin- 6 and sitagliptin treatment group (Fig. 6D and E).

\section{Effects of $\Psi$-xenin-6, sitagliptin or a combination of both compounds on GLP-1 and GIP concentrations as well as DPP-4 activity in HFF mice}

Following the 18-day treatment regimen, all sitagliptin treated mice had significantly $(P<0.01$ and $P<0.001)$ increased circulating total GIP concentrations (Fig. 7A). Interestingly, $\Psi$-xenin- 6 therapy also increased $(P<0.01)$ GIP levels, but did not affect GLP-1 concentrations (Fig. 7A and B). However, the combination treatment group did not present with GIP levels greater than with those with sitagliptin therapy alone (Fig. 7A). High fat feeding reduced $(P<0.001)$ circulating GLP-1, but this was restored to normal lean control levels in all sitagliptin treated mice (Fig. 7B). Plasma DPP-4 activity was significantly $(P<0.05)$ reduced in all HFF mice treated with sitagliptin when compared to HFF control mice (Fig. 7C). DPP-4 activity in the $\Psi$-xenin- 6 treatment group was not significantly altered when compared to lean or high fat control mice (Fig. 7C). To confirm in vivo observations, DPP-4 activity of sitagliptin, $\Psi$-xenin- 6 and a combination of both compounds was evaluated in the in vitro setting (Fig. 7D). In harmony with data from our mouse study, $\Psi$-xenin-6 (10-6 M) had no effect on DPP-4 activity and did not augment sitagliptin-induced reductions of DPP-4 activity (Fig. 7D).

\section{Discussion}

Although DPP-4 inhibitors have undoubted therapeutic benefits in T2DM (Elrishi et al. 2007), their overall effectiveness is perhaps less striking than other clinically approved drugs (Rosenstock et al. 2010). Taking into consideration that the primary pharmacological benefit of DPP-4 inhibition is enhancement of the incretin effect (Gallwitz 2013), known to be severely perturbed in T2DM (Nauck et al. 1993), this is perhaps not overly surprising. In the current study, we sought to address this problem through concurrent administration of the DPP-4 inhibitor, sitagliptin, with the enzymatically stable

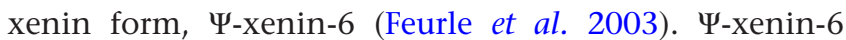
represents a compound known to correct the underlying 

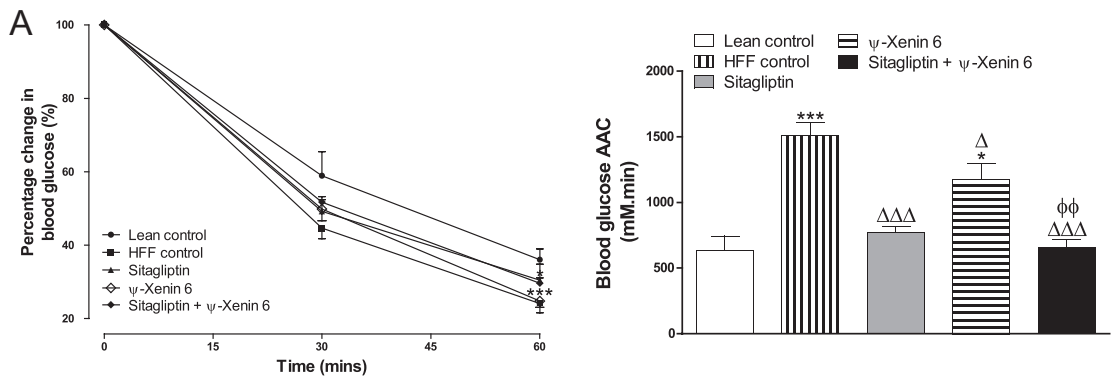

\section{Figure 4}

Effects of 18-day treatment with $\Psi$-xenin-6, sitagliptin or a combination of both compounds on insulin sensitivity and pancreatic insulin content in HFF mice. Parameters were assessed following 18 days of treatment with sitagliptin (50 $\mathrm{mg} / \mathrm{kg}$ bw, p.o., once daily), $\Psi$-xenin-6 ( $25 \mathrm{nmol} / \mathrm{kg}$ bw. i.p. twice daily) or a combination of both compounds using the same dosing regimens. (A) Insulin ( $25 \mathrm{U} / \mathrm{kg}$ bw) was administered by i.p.
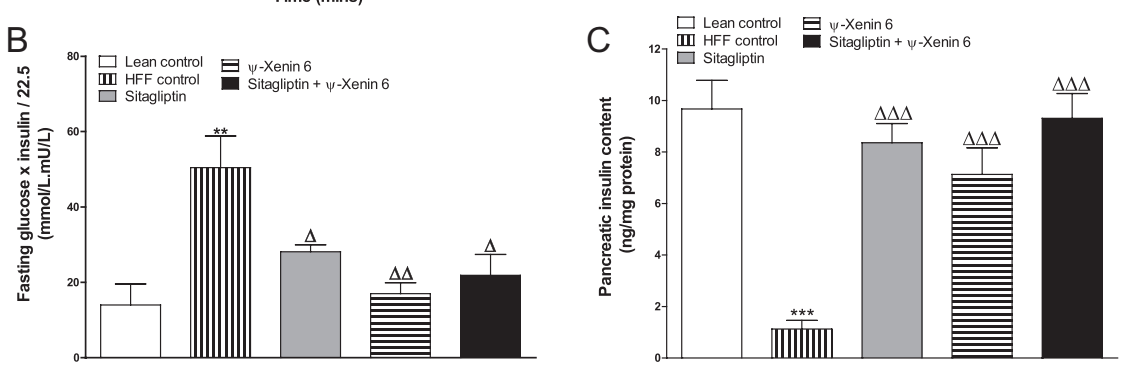
injection at $\mathrm{t}=0 \mathrm{~min}$ in non-fasted mice. Blood glucose AAC values for 0-60 min post injection are shown in the inset. (B) HOMA-IR was calculated by the following equation: fasting glucose $(\mathrm{mmol} / \mathrm{L}) \times$ fasting insulin $(\mathrm{mU} / \mathrm{L}) / 22.5$. (C) Pancreatic insulin content was measured by RIA following acid-ethanol extraction. Values are mean \pm S.E.M. for eight mice. ${ }^{*} P<0.05$ and $\star \star \star P P<0.001$ compared to lean saline controls. $\Delta P<0.05$ and $\Delta \Delta \Delta P<0.001$ compared to HFF saline controls. $\phi \phi P<0.01$ compared to $\Psi$-xenin- 6 alone.
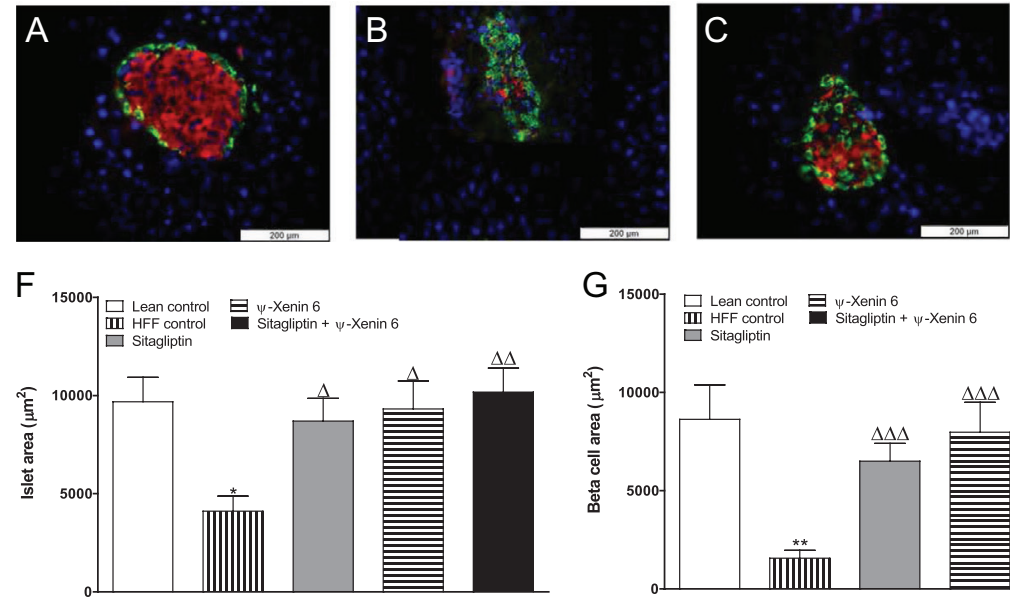

$G_{15000}$
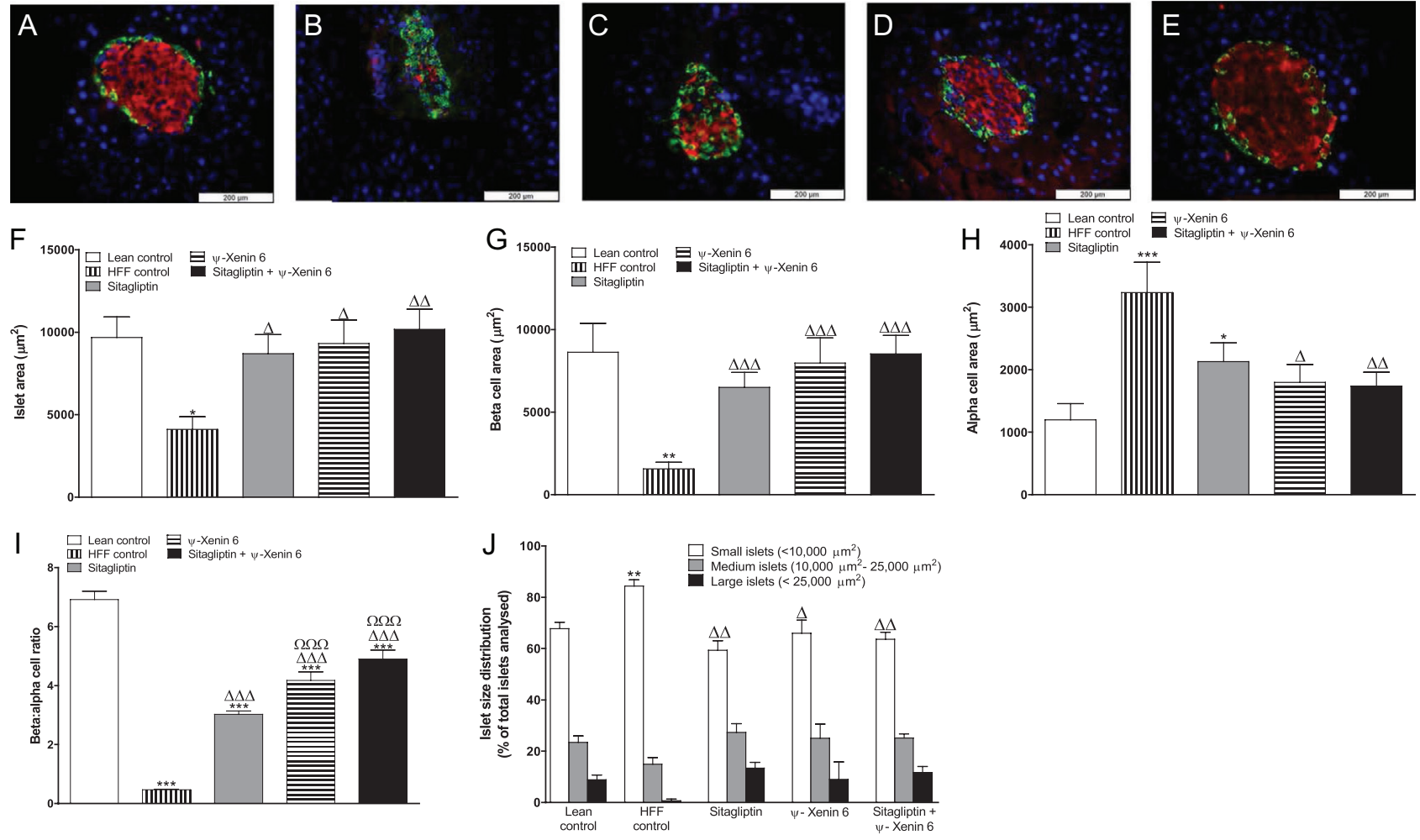

\section{Figure 5}

Effects of 18-day treatment with $\Psi$-xenin-6, sitagliptin or a combination of both compounds on pancreatic islet architecture in HFF mice. Parameters were assessed following 18 days of treatment with sitagliptin ( $50 \mathrm{mg} / \mathrm{kg}$ bw, p.o., once daily), $\Psi$-xenin-6 ( $25 \mathrm{nmol} / \mathrm{kg}$ bw. i.p. twice daily) or a combination of both compounds using the same dosing regimens. (A, B, C, D and E) Representative images (20x) of islets showing insulin (red) and glucagon (green) immunoreactivity from each treatment group. (F) Islet, (G) beta- and (H) alpha-cell areas, as well as (I) beta:alpha area cell area ratio and $(\mathrm{J})$ islet size distribution were measured using CellF image analysis software. Values are mean \pm S.E.M. for eight mice. $* P<0.05, * \star P<0.01$ and $* \star \star P<0.001$ compared to lean controls. $\Delta P<0.05, \Delta \Delta P<0.01$ and $\Delta \Delta \Delta P<0.001$ compared to HFF saline controls. $\Omega \Omega \Omega P<0.001$ compared to sitagliptin alone. A full color version of this figure is available at https://doi.org/10.1530/JOE-19-0557. 
A

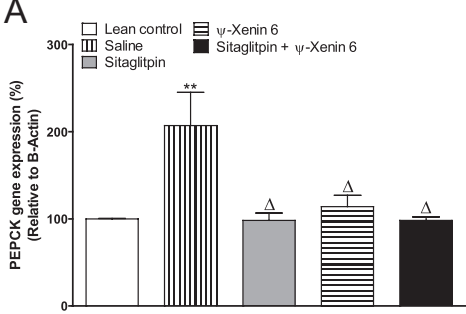

$\mathrm{D}$

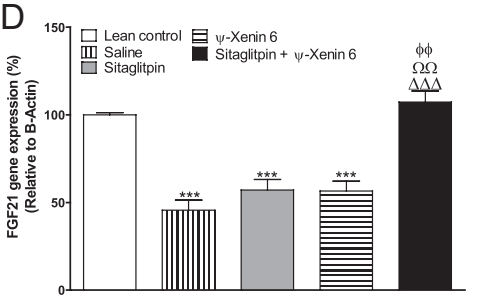

B
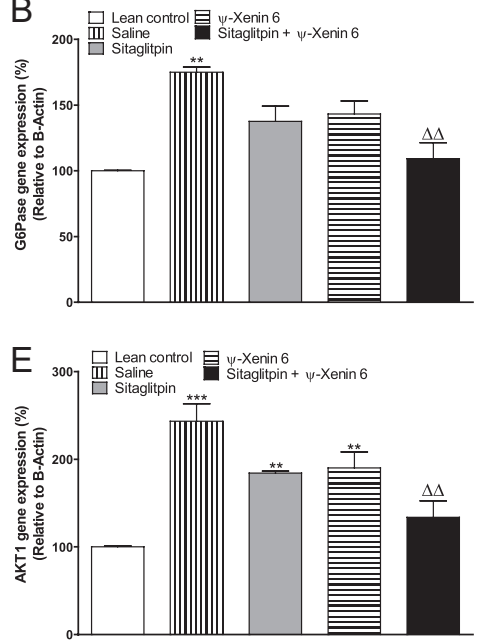

C

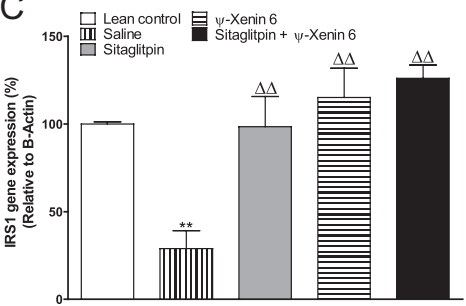

\section{Figure 6}

Effects of 18-day treatment with $\Psi$-xenin-6, sitagliptin or a combination of both compounds on hepatic gene expression in HFF mice. Parameters were assessed following 18 days of treatment with sitagliptin ( $50 \mathrm{mg} / \mathrm{kg}$ bw, p.o., once daily), $\Psi$-xenin-6 (25 nmol/kg bw. i.p. twice daily) or a combination of both compounds using the same dosing regimens. mRNA expression of (A) phosphoenolpyruvate carboxykinase (Pepck), (B) glucose 6-phosphatase (G6pase), (C) insulin receptor substrate-1 (Irs1), (D) fibroblast growth factor 21 (Fgf21) and (E) serine-threonine protein kinase (Akt1) were determined relative to control gene expression ( $\beta$-actin). Values are mean \pm S.E.M. for eight mice. $* P<0.05, * \star P<0.01$ and $* \star \star P<0.001$ compared with lean controls. $\Delta P<0.05, \Delta \Delta P<0.01$ and $\Delta \Delta \Delta P<0.001$ compared to HFF saline controls. $\Omega \Omega P<0.01$ compared to sitagliptin alone. $\phi \phi P<0.01$ compared to $\Psi$-xenin- 6 alone.

incretin defect in T2DM, specifically GIP insensitivity (Craig et al. 2019).

As would be expected, sitagliptin and $\Psi$-xenin-6 therapy induced a number of benefits on metabolism in HFF mice. This is interesting, given that $\Psi$-xenin-6 was administered at a reduced molar concentration when compared to sitagliptin and because HFF mice were also administered two low doses of STZ prior to treatment intervention. Such benefits included reduced glucose levels as well as improved glucose tolerance and insulin sensitivity, with notable improvements in pancreatic islet architecture. Indeed, assessment of peripheral insulin sensitivity would have been even more positive, but for normal adaptive responses in
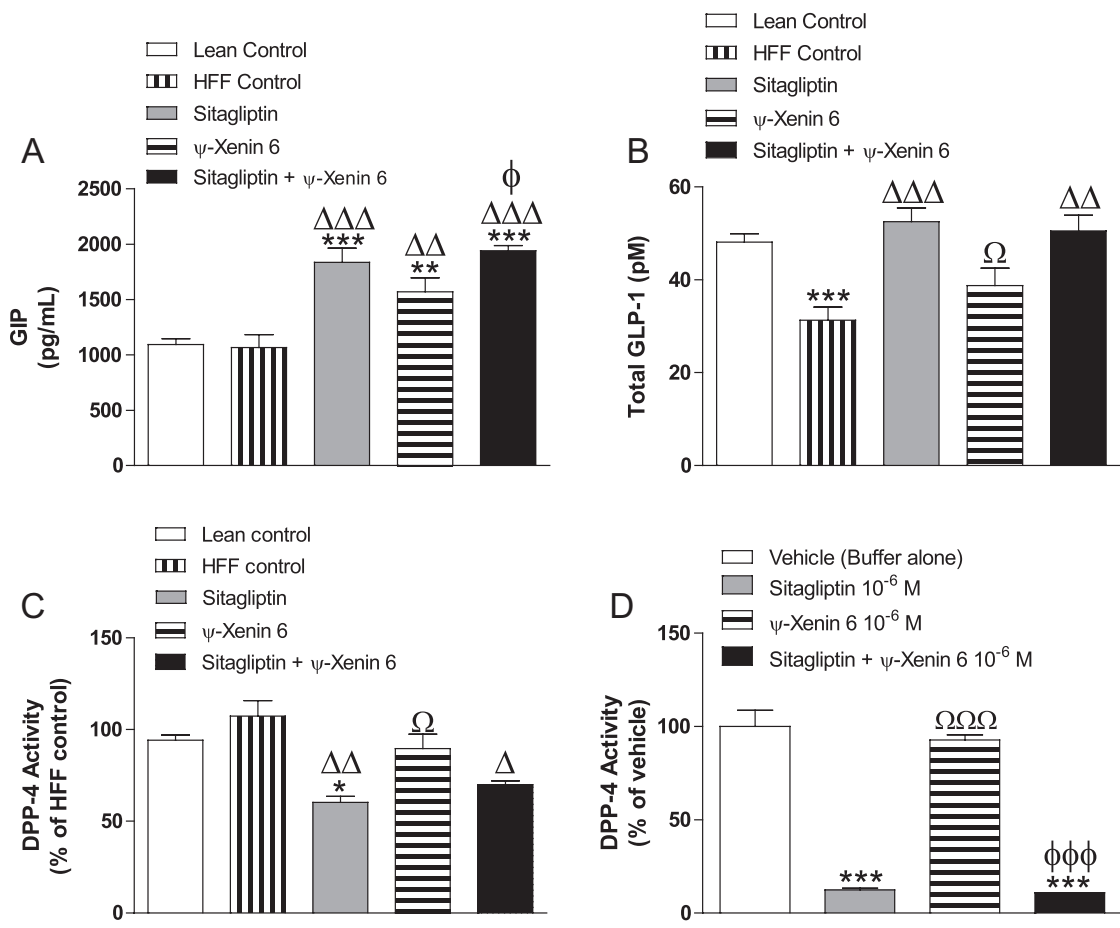

\section{Figure 7}

Effects of $\Psi$-xenin-6, sitagliptin or a combination of both compounds on total GIP and GLP-1 concentrations as well as DPP-4 activity in HFF mice. ( $A, B$ and $C$ ) Parameters were assessed following 18 days of treatment with sitagliptin (50 $\mathrm{mg} / \mathrm{kg}$ bw, p.o., once daily), $\Psi$-xenin-6 $(25 \mathrm{nmol} / \mathrm{kg}$ bw. i.p. twice daily) or a combination of both compounds using the same dosing regimens. Total plasma (A) GIP and (B) GLP-1 concentrations were determined using commercially available ELISA kits. (C) DPP-4 activity was measured in plasma using established procedures (Lindsay et al. 2005). (D) DPP-4 activity of all test compounds $\left(10^{-6} \mathrm{M}\right)$ was also determined in the in vitro setting. Values are mean \pm S.E.M. for (A, B and C) eight mice or (D) four experimental replicates. $\star P<0.05, * * P<0.01$ and $* * * P<0.001$ compared with lean or vehicle control, as appropriate. $\Delta P<0.05, \Delta \Delta P<0.01$ and $\Delta \Delta \Delta P<0.001$ compared to HFF saline controls. $\Omega P<0.05$ and $\Omega \Omega \Omega P<0.001$ compared to sitagliptin alone. $\phi P<0.05$ and $\phi \phi \phi P<0.001$ compared to $\Psi$-xenin- 6 alone. 
these mice to prevent glucose concentrations falling toward life threatening hypoglycaemia levels, following exogenous insulin injection. As expected, positive effects of sitagliptin were linked to elevated circulating GIP and GLP-1 concentrations (Deacon et al. 1998). Interestingly, 世-xenin-6 also increased GIP levels, which may be somewhat unexpected. As such, the secretory dynamics of intestinal K-cells are well established (Gribble \& Reimann 2019), although whether xenin exerts a positive autocrine effect on GIP secretion from K-cells is currently unknown. More importantly, elevated GIP and GLP-1 concentrations of the combined treatment group were not greater than with sitagliptin alone, confirming that benefits of combination therapy are not linked to increased incretin hormone levels.

Despite administration of the specific beta-cell toxin STZ, each of the treatments, namely sitagliptin, $\Psi$-xenin-6 or a combination of both compounds, returned overall islet and beta-cell areas, as well as pancreatic insulin content, to normal levels. It is intriguing to note that, in a related HFF mouse model with STZ-induced defects of insulin secretion, similar benefits of pancreatic islet architecture were observed following sustained administration of an analogue of sitagliptin, namely desfluoro-sitagliptin ( $\mathrm{Mu}$ et al. 2006). In the study by $\mathrm{Mu}$ and co-workers, des-fluoro-sitagliptin was administered for 11 weeks in the diet, as opposed to 18 days oral gavage in the current investigation. Thus, the oral gavage route ensures consistent dosing, drug delivery and faster onset of action, which may not always be the case with drug-supplemented animal diets. Whether augmented pancreatic insulin content in the current study was due to increases in beta-cell proliferation, reductions of beta-cell apoptosis or increased insulin production within betacells still needs to be determined. However, the beneficial impact of such pancreatic changes was clearly apparent on circulating insulin concentrations, with steady augmentations being evident in the combined treatment group. In keeping with this, GIP, GLP-1 and xenin have been shown to independently stimulate insulin secretion (Schmidt et al. 1985, Taylor et al. 2010), as well as promote pancreatic beta-cell growth and survival (Vilsbøll \& Holst 2004, Drucker 2006, Khan et al. 2017). In addition to this, intra-islet synthesis and secretion of GLP-1 have previously been shown to play a fundamental role in appropriate pancreatic islet adaptations to various diabetes-like disease states (Moffett et al. 2014, Vasu et al. 2014). As such, it would have been interesting to assess pancreatic islet levels of both GLP-1 and GIP in the current study. Nonetheless, dual treatment with sitagliptin and $\Psi$-xenin-6 evoked rapid improvements in glycaemic status, beyond that observed with either treatment alone. Such benefits were more apparent in the fed, as opposed to fasted, state, as evidenced during glucose tolerance testing that revealed no differences between the treatment regimens. This could simply be a consequence of the primary metabolic benefits of GIP, GLP-1 and xenin being more associated with the postprandial setting (Chowdhury et al. 2014, Irwin \& Flatt 2015). Lack of benefit of combined treatment intervention on glucose tolerance and related insulin secretion is somewhat surprising and may require further investigation.

Although benefits on circulating insulin and pancreatic morphology were evident, none of the treatments increased the insulin response to exogenous glucose on day 18. Furthermore, there was a significant improvement in peripheral insulin sensitivity in all treated HFF mice, suggesting that improvements in glycaemic control were not solely a result of pancreatic-related benefits and could be related to the weight loss induced by each treatment. Indeed, hepatic expression of Irs1 was augmented to a similar level by all treatment interventions. Moreover, combined sitagliptin and $\Psi$-xenin- 6 therapy also increased Fgf21 expression in the liver and returned mRNA levels of hepatic Akt1 to that of lean controls, both of which would improve insulin action (Kim et al. 2000, Emanuelli et al. 2014). However, whether these positive changes in gene expression are independent of body weight loss still needs to be determined. Moreover, further investigation of the FGF21-adiponectin axis (Hui et al. 2016), in relation to the established crosstalk between the liver and adipose tissue that is known to be important for overall glucose homeostasis (Ye et al. 2017), would also be of interest here. In keeping with insulin action, hepatic gluconeogenesis was decreased in all treatment groups, but particularly by combined therapy, as established through assessment of pyruvate tolerance. In this respect, hyperinsulinaemic clamp studies may have given a more consistent readout of hepatic glucose production, but are beyond the scope of the current study. Nonetheless, irregular carbohydrate metabolism and inappropriate pyruvate flux are well known to be associated with diabetes and obesity (Gao et al. 2009, Singla et al. 2010). To further support the notion that sitagliptin and $\Psi$-xenin-6 diminish hepatic gluconeogenesis, we determined expression of Pepck and G6pase in liver tissue, key signalling molecules in the gluconeogenesis pathway (Lochhead et al. 2000). As such, PEPCK and G6Pase are fundamental in the initial and final steps, respectively, of the gluconeogenic pathway (Hers \& Hue 1983). Only combined sitagliptin and $\Psi$-xenin-6 
treatment significantly reduced the expression of both genes, and although some obvious restraint is required in interpretation, especially since individual treatments also evoked reductions in the expression of these genes, this does suggest that the expression and subsequent biological function of these proteins could be a major factor in the improvement of gluconeogenesis. In addition, it would also have been interesting to assess plasma and tissue lipid status in these mice, as well as genes involved in lipid flux. Moreover, assessment of related protein expression would be required to confirm overall relevance of the observed changes in gene expression.

Despite knowledge of the weight neutral effects of DPP-4 inhibitors (Foley \& Jordan 2010), as well as lack of effect of prolonged administration of enzymatically stable versions of xenin on body weight in diabetic mice (Gault et al. 2015a, Martin et al. 2016, Parthsarathy et al. 2016), both sitagliptin and $\Psi$-xenin- 6 reduced body weight gain in the current setting. Moreover, combined treatment in HFF mice resulted in body weight change that was not different to lean controls, despite similar energy intake in all groups of HFF mice. In keeping with this, lack of effect of sitagliptin and xenin peptides on feeding has previously been observed in rodents using the same dosing regimens employed here (Taylor et al. 2010, Gault et al. $2015 b$, Hasib et al. 2017). In view of the role of obesity in the development of T2DM (Al-Goblan et al. 2014), and the comparable increasing prevalence of both conditions (Agha \& Agha 2017), this more pronounced body weight lowering effect could represent an attractive therapeutic effect of combined therapy. As such, it is well recognised that the central pathways controlling energy balance display notable plasticity (Irwin \& Flatt 2015), and thus concurrent positive modulation of signal transduction proteins linked to both compounds may be essential to yield such appreciable benefits. A reduction of body weight could also be a contributing factor to improved metabolic effects of the combination treatment (Wilding 2014), although further assessment of body composition, locomotor activity and metabolic rate, including energy expenditure, would be required to fully assess this.

Taken together, data presented within the current study support the view that the antidiabetic benefits of DPP-4 inhibitors can be augmented. Importantly, assessment of DPP-4 activity on day 18, together with in vitro observations, demonstrated that $\Psi$-xenin- 6 does not augment DPP-4 inhibitory activity of sitagliptin. Given that incretin hormone levels were also not increased by dual administration of $\Psi$-xenin- 6 and sitagliptin, it suggests that the likely benefit of combined therapy is linked to the augmentation of GIP bioactivity by $\Psi$-xenin-6, as has been previously established (Craig et al. 2019). Observations of improved effects of combined $\Psi$-xenin- 6 and sitagliptin treatment on body weight, circulating glucose and insulin, attenuation of gluconeogenesis, as well as improvements in pancreatic islet morphology are encouraging, especially over a relatively short treatment period of 18 days. However, it should be noted that combined therapy did not improve glucose tolerance beyond that observed with either treatment alone. Nonetheless, clinical studies already confirm some enhanced antidiabetic efficacy when using combinational therapies that incorporate DPP-4 inhibitor drugs (Goldstein et al. 2007, Barnett et al. 2015), in line with National Institute for Health and Care Excellence (NICE) T2DM treatment guidelines, corroborating proof of concept. Taking into account that $\Psi$-xenin-6 positively regulates the primary therapeutic target of DPP-4 inhibitors, unlike other available antidiabetic medications, the current therapeutic regimen represents an attractive novel option for T2DM that warrants further investigation.

\section{Declaration of interest}

V A G and N I are named on patents filed by the Ulster University for the exploitation of incretin-based drugs and other peptide therapeutics. The other authors have nothing to disclose.

\section{Funding}

These studies were supported by the Invest Northern Ireland Proof of Concept funding, European Foundation for the Study of Diabetes and Department for the Economy, Northern Ireland.

\section{Author contribution statement}

$\mathrm{N} \mathrm{I}, \mathrm{G} \mathrm{H}$ and V A G contributed to the overall concept and experimental design and reviewed the manuscript. S L C researched data, contributed to data interpretation and edited the manuscript. N I and S L C wrote the manuscript. All authors approved the final version of this manuscript.

\section{References}

Agha M \& Agha R 2017 The rising prevalence of obesity: part A: impact on public health. International Journal of Surgical Oncology 2 e17.

Ahrén B 2007 Dipeptidyl peptidase-4 inhibitors: clinical data and clinical implications. Diabetes Care 30 1344-1350. (https://doi.org/10.2337/ dc07-0233)

Al-Goblan AS, Al-Alfi MA \& Khan MZ 2014 Mechanism linking diabetes mellitus and obesity. Diabetes, Metabolic Syndrome and Obesity: Targets and Therapy 7 587-591. (https://doi.org/10.2147/DMSO.S67400) 
Baggio LL \& Drucker DJ 2007 Biology of incretins: GLP-1 and GIP. Gastroenterology 132 2131-2157. (https://doi.org/10.1053/j. gastro.2007.03.054)

Barnett AH, Charbonnel B, Moses RG \& Kalra S 2015 Dipeptidyl peptidase- 4 inhibitors in triple oral therapy regimens in patients with type 2 diabetes mellitus. Current Medical Research and Opinion 31 1919-1931. (https://doi.org/10.1185/03007995.2015.1081589)

Bennettt RG 2018 Sitagliptin. Reference Module in Biomedical Sciences. Elsevier.

Bhat VK, Kerr BD, Flatt PR \& Gault VA 2013 A novel GIP-oxyntomodulin hybrid peptide acting through GIP, glucagon and GLP-1 receptors exhibits weight reducing and anti-diabetic properties. Biochemical Pharmacology 85 1655-1662. (https://doi.org/10.1016/j. bcp.2013.03.009)

Chowdhury S, Reeds DN, Crimmins DL, Patterson BW, Laciny E, Wang S, Tran HD, Griest TA, Rometo DA, Dunai J, et al. 2014 Xenin-25 delays gastric emptying and reduces postprandial glucose levels in humans with and without type 2 diabetes. American Journal of Physiology: Gastrointestinal and Liver Physiology 306 G301-G309. (https://doi. org/10.1152/ajpgi.00383.2013)

Coskun T, Sloop KW, Loghin C, Alsina-Fernandez J, Urva S, Bokvist KB, Cui X, Briere DA, Cabrera O, Roell WC, et al. 2018 LY3298176, a novel dual GIP and GLP-1 receptor agonist for the treatment of type 2 diabetes mellitus: from discovery to clinical proof of concept. Molecular Metabolism 18 3-14. (https://doi.org/10.1016/j. molmet.2018.09.009)

Craig SL, Gault VA \& Irwin N 2018 Emerging therapeutic potential for xenin and related peptides in obesity and diabetes. Diabetes/ Metabolism Research and Reviews 34 e3006. (https://doi.org/10.1002/ dmrr.3006)

Craig SL, Gault VA, McClean S, Hamscher G \& Irwin N 2019 Effects of an enzymatically stable C-terminal hexapseudopeptide fragment peptide of xenin-25, $\psi$-xenin-6, on pancreatic islet function and metabolism. Molecular and Cellular Endocrinology 496 110523. (https:// doi.org/10.1016/j.mce.2019.110523)

Deacon CF 2019 Physiology and pharmacology of DPP-4 in glucose homeostasis and the treatment of Type 2 diabetes. Frontiers in Endocrinology 10 80. (https://doi.org/10.3389/fendo.2019.00080)

Deacon CF, Hughes TE \& Holst JJ 1998 Dipeptidyl peptidase IV inhibition potentiates the insulinotropic effect of glucagon-like peptide 1 in the anesthetized pig. Diabetes 47 764-769. (https://doi.org/10.2337/ diabetes.47.5.764)

Drucker DJ 2006 The biology of incretin hormones. Cell Metabolism 3 153-165. (https://doi.org/10.1016/j.cmet.2006.01.004)

Elrishi MA, Khunti K, Jarvis J \& Davies MJ 2007 The dipeptidylpeptidase-4 (DPP-4) inhibitors: a new class of oral therapy for patients with type 2 diabetes mellitus. Practical Diabetes International $\mathbf{2 4}$ 474-482. (https://doi.org/10.1002/pdi.1181)

Emanuelli B, Vienberg SG, Smyth G, Cheng C, Stanford KI, Arumugam M, Michael MD, Adams AC, Kharitonenkov A \& Khan CR 2014 Interplay between FGF21 and insulin action in the liver regulates metabolism. Journal of Clinical Investigation 124 515-527. (https://doi.org/10.1172/JCI67353)

Feurle GE, Meyer HE \& Hamscher G 2003 Metabolism and potency of xenin and of its reduced hexapseudopeptide $\psi$-fragment in the dog. Life Sciences 74 697-707. (https://doi.org/10.1016/j.lfs.2003.05.009)

Flatt PR \& Bailey CJ 1982 Plasma glucose and insulin response to glucagon and arginine in Aston ob/ob mice: evidence for a selective defect in glucose-mediated insulin release. Hormone and Metabolic Research 14 127-130. (https://doi.org/10.1055/s-2007-1018945)

Foley JE \& Jordan J 2010 Weight neutrality with the DPP-4 inhibitor, vildagliptin: mechanistic basis and clinical experience. Vascular Health and Risk Management 6 541-548. (https://doi.org/10.2147/vhrm. s10952)

Frias JP, Nauck MA, Van J, Kutner ME, Cui X, Benson C, Urva S, Gimeno RE, Milicevic Z, Robins D, et al. 2018 Efficacy and safety of
LY3298176, a novel dual GIP and GLP-1 receptor agonist, in patients with type 2 diabetes: a randomised, placebo-controlled and active comparator-controlled phase 2 trial. Lancet 392 2180-2193. (https:// doi.org/10.1016/S0140-6736(18)32260-8)

Gallwitz B 2013 Emerging DPP-4 inhibitors: focus on linagliptin for type 2 diabetes. Diabetes, Metabolic Syndrome and Obesity: Targets and Therapy 6 1-9. (https://doi.org/10.2147/DMSO.S23166)

Gao XF, Chen W, Kong XP, Xu AM, Wang ZG, Sweeney G \& Wu D 2009 Enhanced susceptibility of Cpt1c knockout mice to glucose intolerance induced by a high-fat diet involves elevated hepatic gluconeogenesis and decreased skeletal muscle glucose uptake. Diabetologia 52 912-920. (https://doi.org/10.1007/s00125-009-1284-0)

Gault VA, Martin CM, Flatt PR, Parthsarathy V \& Irwin N 2015a Xenin25[Lys13PAL]: a novel long-acting acylated analogue of xenin-25 with promising antidiabetic potential. Acta Diabetologica 52 461-471. (https://doi.org/10.1007/s00592-014-0681-0)

Gault VA, Lennox R \& Flatt PR 2015b Sitagliptin, a dipeptidyl peptidase-4 inhibitor, improves recognition memory, oxidative stress and hippocampal neurogenesis and upregulates key genes involved in cognitive decline. Diabetes, Obesity and Metabolism 17 403-413. (https://doi.org/10.1111/dom.12432)

Goldstein BJ, Feinglos MN, Lunceford JK, Johnson J, Williams-Herman DE \& Sitagliptin 036 Study Group 2007 Effect of initial combination therapy with sitagliptin, a dipeptidyl peptidase- 4 inhibitor, and metformin on glycemic control in patients with Type 2 diabetes. Diabetes Care 30 1979-1987. (https://doi.org/10.2337/dc07-0627)

Gribble FM \& Reimann F 2019 Function and mechanisms of enteroendocrine cells and gut hormones in metabolism. Nature Reviews: Endocrinology 15 226-237. (https://doi.org/10.1038/s41574019-0168-8)

Hasib A, NG MT, Gault VA, Khan D, Parthsarathy V, Flatt PR \& Irwin N 2017 An enzymatically stable GIP/xenin hybrid peptide restores GIP sensitivity, enhances beta cell function and improves glucose homeostasis in high-fat-fed mice. Diabetologia 60 541-552. (https:// doi.org/10.1007/s00125-016-4186-y)

Hers HG \& Hue L 1983 Gluconeogenesis and related aspects of glycolysis. Annual Review of Biochemistry 52 617-653. (https://doi.org/10.1146/ annurev.bi.52.070183.003153)

Holst JJ \& Ørskov C 2004 The incretin approach for diabetes treatment: modulation of islet hormone release by GLP-1 agonism. Diabetes $\mathbf{5 3}$ (Supplement 3) S197-S204. (https://doi.org/10.2337/diabetes.53. suppl_3.s197)

Hui X, Feng T, Liu Q, Gao Y \& Xu A 2016 The FGF21-adiponectin axis in controlling energy and vascular homeostasis. Journal of Molecular Cell Biology 8 110-119. (https://doi.org/10.1093/jmcb/mjw013)

Irwin N \& Flatt PR 2015 New perspectives on exploitation of incretin peptides for the treatment of diabetes and related disorders. World Journal of Diabetes 6 1285-1295. (https://doi.org/10.4239/wjd. v6.i15.1285)

Irwin N, Pathak V \& Flatt PR 2015 A novel CCK-8/GLP-1 hybrid peptide exhibiting prominent insulinotropic, glucose-lowering and satiety actions with significant therapeutic potential in high-fat fed mice. Diabetes 64 2996-3009. (https://doi.org/10.2337/db15-0220)

Khajavi N, Biebermann H, Tschöp M \& DiMarchi R 2017 Treatment of diabetes and obesity by rationally designed peptide agonists functioning at multiple metabolic receptors. Endocrine Development 32 165-182. (https://doi.org/10.1159/000475737)

Khan D, Vasu S, Moffett RC, Gault VA, Flatt PR \& Irwin N 2017 Locally produced xenin and the neurotensinergic system in pancreatic islet function and $\beta$-cell survival. Biological Chemistry 399 79-92. (https:// doi.org/10.1515/hsz-2017-0136)

Kim YB, Peroni OD, Franke TF \& Kahn BB 2000 Divergent regulation of Akt1 and Akt2 isoforms in insulin target tissues of obese Zucker rats. Diabetes 49 847-856. (https://doi.org/10.2337/diabetes.49.5.847)

Knop FK \& Taylor R 2013 Mechanism of metabolic advantages after bariatric surgery: it's all gastrointestinal factors versus it's all food https://joe.bioscientifica.com

https://doi.org/10.1530/JOE-19-0557 (c) 2020 Society for Endocrinology Published by Bioscientifica Ltd. Printed in Great Britain 
restriction. Diabetes Care 36 (Supplement 2) S287-S291. (https://doi. org $/ 10.2337 / \mathrm{dcS} 13-2032)$

Knop FK, Vilsbøll T, Højberg PV, Larsen S, Madsbad S, Vølund A, Holst JJ \& Krarup T 2007 Reduced incretin effect in Type 2 diabetes: cause or consequence of the diabetic state? Diabetes 56 1951-1959. (https:// doi.org/10.2337/db07-0100)

Lindsay JR, Duffy NA, McKillop AM, Ardill J, O'Harte FP, Flatt PR \& Bell PM 2005 Inhibition of dipeptidyl peptidase IV activity by oral metformin in Type 2 diabetes. Diabetic Medicine 22 654-657. (https:// doi.org/10.1111/j.1464-5491.2005.01461.x)

Lochhead PA, Salt IP, Walker KS, Hardie DG \& Sutherland C 2000 5-Aminoimidazole-4-carboxamide riboside mimics the effects of insulin on the expression of the 2 key gluconeogenic genes PEPCK and glucose-6-phosphatase. Diabetes 49 896-903. (https://doi. org/10.2337/diabetes.49.6.896)

Martin CM, Gault VA, McClean S, Flatt PR \& Irwin N 2012 Degradation, insulin secretion, glucose-lowering and GIP additive actions of a palmitate-derivatised analogue of xenin-25. Biochemical Pharmacology 84 312-319. (https://doi.org/10.1016/j.bcp.2012.04.015)

Martin CM, Parthsarathy V, Pathak V, Gault VA, Flatt PR \& Irwin N 2014 Characterisation of the biological activity of xenin-25 degradation fragment peptides. Journal of Endocrinology 221 193-200. (https://doi. org/10.1530/JOE-13-0617)

Martin CM, Parthsarathy V, Hasib A, NG MT, McClean S, Flatt PR, Gault VA \& Irwin N 2016 Biological activity and antidiabetic potential of C-terminal octapeptide fragments of the gut-derived hormone xenin. PLOS ONE 11 e0152818. (https://doi.org/10.1371/journal. pone.0152818)

Moffett RC, Irwin N, Francis JM \& Flatt PR 2013 Alterations of glucosedependent insulinotropic polypeptide and expression of genes involved in mammary gland and adipose tissue lipid metabolism during pregnancy and lactation. PLOS ONE 8 e78560. (https://doi. org/10.1371/journal.pone.0078560)

Moffett RC, Vasu S, Thorens B, Drucker DJ \& Flatt PR 2014 Incretin receptor null mice reveal key role of GLP-1 but not GIP in pancreatic beta cell adaptation to pregnancy. PLOS ONE 9 e96863. (https://doi. org/10.1371/journal.pone.0096863)

Mu J, Woods J, Zhou YP, Roy RS, Li Z, Zycband E, Feng Y, Zhu L, Li C, Howard AD, et al. 2006 Chronic inhibition of dipeptidyl peptidase- 4 with a sitagliptin analog preserves pancreatic $\beta$-cell mass and function in a rodent model of type 2 diabetes. Diabetes 55 1695-1704. (https:// doi.org/10.2337/db05-1602)

Nauck MA, Heimesaat MM, Orskov C, Holst JJ, Ebert R \& Creutzfeldt W 1993 Preserved incretin activity of glucagon-like peptide 1 [7-36 amide] but not of synthetic human gastric inhibitory polypeptide in patients with type-2 diabetes mellitus. Journal of Clinical Investigation 91 301-307. (https://doi.org/10.1172/JCI116186)

O’Harte FPM, Gray AM \& Flatt PR 1998 Gastric inhibitory polypeptide and effects of glycation on glucose transport and metabolism in isolated mouse abdominal muscle. Journal of Endocrinology $\mathbf{1 5 6}$ 237-243. (https://doi.org/10.1677/joe.0.1560237)

Parthsarathy V, Irwin N, Hasib A, Martin CM, McClean S, Bhat VK, Ng MT, Flatt PR \& Gault VA 2016 A novel chemically modified analogue of xenin-25 exhibits improved glucose-lowering and insulin-releasing properties. Biochimica et Biophysica Acta 1860 757-764. (https://doi.org/10.1016/j.bbagen.2016.01.015)

Rosenstock J, Klaff LJ, Schwartz S, Northrup J, Holcombe JH, Wilhelm K \& Trautmann M 2010 Effects of exenatide and lifestyle modification on body weight and glucose tolerance in obese subjects with and without pre-diabetes. Diabetes Care 33 1173-1175. (https://doi.org/10.2337/ dc09-1203)

Schmidt WE, Siegel EG \& Creutzfeldt W 1985 Glucagon-like peptide-1 but not glucagon-like peptide- 2 stimulates insulin release from isolated rat pancreatic islets. Diabetologia 28 704-707. (https://doi. org/10.1007/bf00291980)

Scott LJ 2017 Sitagliptin: a review in Type 2 diabetes. Drugs 77 209-224. (https://doi.org/10.1007/s40265-016-0686-9)

Singla P, Bardoloi A \& Parkash AA 2010 Metabolic effects of obesity: a review. World Journal of Diabetes 1 76-88. (https://doi.org/10.4239/ wjd.v1.i3.76)

Taylor AI, Irwin N, McKillop AM, Patterson S, Flatt PR \& Gault VA 2010 Evaluation of the degradation and metabolic effects of the gut peptide xenin on insulin secretion, glycaemic control and satiety. Journal of Endocrinology 207 87-93. (https://doi.org/10.1677/JOE-100085)

Vasu S, Moffett RC, Thorens B \& Flatt PR 2014 Role of endogenous GLP-1 and GIP in beta cell compensatory responses to insulin resistance and cellular stress. PLoS ONE 9 e101005. (https://doi.org/10.1371/journal. pone.0101005)

Vilsbøll T \& Holst JJ 2004 Incretins, insulin secretion and type 2 diabetes mellitus. Diabetologia 47 357-366. (https://doi.org/10.1007/s00125004-1342-6)

Vincent RP \& Le Roux CW 2008 Changes in gut hormones after bariatric surgery. Clinical Endocrinology 69 173-179. (https://doi.org/10.1111/ j.1365-2265.2007.03164.x)

Wice BM, Wang S, Crimmins DL, Diggs-Andrews KA, Althage MC, Ford EL, Tran H, Ohlendorf M, Griest TA, Wang Q, et al. 2010 Xenin-25 potentiates glucose-dependent insulinotropic polypeptide action via a novel cholinergic relay mechanism. Journal of Biological Chemistry 285 19842-19853. (https://doi.org/10.1074/jbc. M110.129304)

Wilding JP 2014 The importance of weight management in type 2 diabetes mellitus. International Journal of Clinical Practice 68 682-691. (https://doi.org/10.1111/ijcp.12384)

Ye DW, Rong XL, Xu AM \& Guo J 2017 Liver-adipose tissue crosstalk: a key player in the pathogenesis of glucolipid metabolic disease. Chinese Journal of Integrative Medicine 23 410-414. (https://doi.org/10.1007/ s11655-017-2810-4)

Received in final form 27 February 2020

Accepted 4 March 2020

Accepted Manuscript published online 4 March 2020 https://joe.bioscientifica.com https://doi.org/10.1530/JOE-19-0557 (c) 2020 Society for Endocrinology Published by Bioscientifica Ltd. Printed in Great Britain 